Article

\title{
Psychometric properties of SCARED-C Scale in a Romanian community sample and its future utility for dental practice
}

\author{
Sorana-Maria Bucur ${ }^{1}$, Adela Moraru ${ }^{2}$, Beata Adamovits ${ }^{2}$, Eugen Silviu Bud ${ }^{3 *}$, Cristian Doru Olteanu ${ }^{4, *}$ and Lu- \\ minița Ligia Vaida ${ }^{5}$
}

1 Faculty of Medicine, University Dimitrie Cantemir, 540545 Târgu-Mureș, Romania; $\underline{\text { bucur- }}$ soranamaria@gmail.com

2 Faculty of Psychology, University Dimitrie Cantemir, 540545 Târgu-Mureș, Romania; moraruadela@gmail.com (M.A.); adamovitsbeata@gmail.com (A.B.)

3 Faculty of Dental Medicine,University of Medicine and Pharmacy, Science and Technology George Emil Palade, 540139 Târgu-Mureș, Romania; Eugen.bud@umfst.ro

4 Faculty of Dental Medicine, Iuliu Hațieganu University of Medicine and Pharmacy, 8 Babeș Str., 400012 Cluj-Napoca, Romania; cristidolteanu@yahoo.com

5 Faculty of Medicine and Pharmacy, Department of Dentistry, 1 Universității Str., 410087 Oradea, Romania; ligia vaida@yahoo.com

*Correspondence: Eugen.bud@umfst.ro (B.E.S.); ligia_vaida@yahoo.com (V.L.L.)

\begin{abstract}
SCARED-C instrument (the child version, 41 items) is used for screening anxiety in children between 8 to 18 years old and has been first introduced by Birmaher \& colab. in 1995, with good psychometric data - internal consistency from $\alpha=.74$ to .93 - and good discriminative validity indices in the original versions $(1997,1999)$. Since then, many countries have adopted the scale for its utility in identifying five subsets of anxiety disorders (subscales): somatic/panic disorder, generalized anxiety, separation anxiety, social phobia, and school avoidance. The present study contains the first Romanian translated and adapted version of the SCARED-C instrument in a community sample of 477 children (8-18 years old) from Mureș county schools. The instrument showed moderate to good internal consistency ( $\alpha$ Cronbach from to .63 to .91 for the total scale) and good test-retest reliability (.70) on a subset of 85 children sample. A confirmatory factorial analysis (CFA) was conducted to test the factor structure of the Romanian version of SCARED-C; results showed that SCARED-C has good psychometric properties to be used for screening anxiety in Romanian children and adolescents. The implications for using SCARED-C in dental practice are discussed. Future studies need to be conducted for exploring convergent and discriminative validity of the instrument and the sensitivity to current DSM-V criteria. Application on a dental pediatric sample is also required.
\end{abstract}

Keywords: child anxiety disorders; screening; SCARED-C; psychometrics; dental practice

\section{INTRODUCTION}

\subsection{General introduction to the studied problem}

Psychological management of children and adolescents in need of pedodontic or orthodontic treatments continues to be an essential objective in dental activity because, along with the accuracy of the techniques used, anxiety reduction and knowledge of 
approaching the patient are necessary for the treatments' success. Usually, the fear of pain or trauma is what causes anxiety. In turn, anxiety accentuates and amplifies the pain caused by the dental procedures performed, thus creating a vicious circle that must be interrupted by the intervention of the doctor [1].

The present paper is focused on the SCARED-C Scale validation for the Romanian population, and the motivation for choosing this psychological test is that it can determine the patient's type of anxiety that is crucial for the future approach of the dentist and the overall collaboration with the patient. The dentist's attitude and intervention to reduce the patient's anxiety can be adapted later to the type of anxiety demonstrated by the patient who completed the questionnaire.

\subsection{The importance of the problem - arguments in mental health and dental practice. Definition of terms}

General anxiety is considered an irrational fear without a motivation known to the subject and unexplained by another mental illness or organic condition [2]. It is a permanent or almost permanent emotional condition that cannot be influenced by the patient himself/herself. Anxiety manifests itself either acutely when we are dealing with the state anxiety or continuously and diffusely, in which case we are dealing with general anxiety or anxiety as a trait [3].

Clinical anxiety could have many forms that have been described by the fifth version of the Handbook of Diagnosis and Statistics of Mental Disorders, developed by the American Psychiatric Association (APA) [4].

Separation anxiety is one of the most common anxiety disorders of childhood, along with generalized anxiety and specific phobias. According to the American Psychiatric Association, the main feature of separation anxiety is the fear caused by the idea of separation from family, from people to whom the person has a strong emotional attachment or from home that is greater than the natural concern specific to the degree of mental development of the child [4]. Separation anxiety could be a normal psychological condition in the early childhood [5] but presents a risk to influence the child's social and emotional functioning when it persists at an older age and leads to the avoidance of some places, activities, and experiences necessary for a healthy development. The separation anxiety disorder with severe symptoms can lead to school dropout and disruption of education [6]. Separation anxiety proved to be strongly correlated with dental anxiety and phobia [7].

In the same psychiatric classification, general anxiety is characterized by deep, unrealistic, and exaggerated concern about various situations that are perceived as threatening [4]. It is the exaggerated fear and worries about common things. These individuals find it difficult to control their anxiety. The presence of increased anxiety affects the mental development of children and their daily activities. The diagnosis of generalized anxiety is put if excessive care is present almost every day for 6 months and if the person has difficulty controlling anxiety. In addition, the person may experience one or more of the following symptoms: irritability, fatigue, insomnia, concentration problems (does not feel able to think) [4]. Children and adolescents with general anxiety will have higher values of dental anxiety than others [8,9].

Social anxiety is a common psychological disorder causing other behavioral, psychological even psychiatric problems like severe anxiety and depression [10]. Young people with social anxiety could feel fear and difficulties even in normal interactional situations with a negative impact on their social life [11]. Their fears are exacerbated in the presence of a factor considered potentially aggressive such as the dental treatment. Social anxiety was already included in the category of psychiatric disorders by the Diagnostic and Statistical Manual of Mental Disorders, third edition; this condition has been regarded since then as a phobia caused by various social situations [12]. Social phobia consists in the fear of evaluation and negative judgment of other people [13]. 
That's why people with social phobia are afraid to do something that could humiliate them in front of the public. Those who suffer from social phobia may feel fear in one case or in several situations, and thatto isolation [14].

The American Psychiatric Association describes another emotional disorder called selective mutism which often coincides with social phobia with comorbidity rates up to 97\% [15]. This psychological disorder could manifest in childhood or adolescence and is characterized by the inability to speak in specific social situations, such as the classroom or the dental office, while in common situations, at home with the family, the individual speaks and communicates easily $[15,16]$.

It has been demonstrated that a high level of dental anxiety (dental fear) has a strong positive correlation with a high level of comorbid phobias like depression, mood disorders, and other psychiatric pathologies and symptoms. It was not possible to establish exactly whether patients with dental anxiety are more prone to have other psychiatric disorders, or whether other psychiatric conditions are the primary disorder predisposing an individual to the development of dental anxiety [17]. The challenge for the dentist is to deal with a patient with dental anxiety or to choose the easiest way and advise the patient to consult a psychologist or a psychiatrist [17].

\subsection{Methods of screening children's anxiety in psychological or dental practice}

The psychological diagnosis is made through various methods, either by using test batteries or by clinical interviews. Currently, in psychology there is a wide range of methods and techniques to study anxiety: one of the most used methods and those that provide the most information are tests and questionnaires. Often, the tests do not replace the clinical diagnosis of a specialist but can help to highlight symptoms of anxiety that are indicated to be alleviated by various methods even by the dentist $[18,19,20]$.

Very often in the clinical activity, the dentist or the orthodontist might notice the patients' anxiety and behavioral changes. Even for experienced doctors, the approach to an anxious patient is often empirical, based on outdated techniques or concepts. The doctor and the patient are two people facing each other from different positions, both being in stressful situations. The communication between them becomes even more difficult when the doctor is at the beginning of his career, is a less empathetic person, or even himself is stressed by the burden of professional responsibility, the difficulty of the case, and the poor professional training [21]. These two people need to adjust to each other, being necessary for the doctor to control the situation and reduce the patient's anxiety by directly influencing the patient, the proper organization of his work, and the dental offices' environment.

Anxiety assessment by questionnaire could give practical information for the dentist and may also bring psychological benefits to the patients. Dayley \& all. (2002) demonstrated that by completing an anxiety assessment questionnaire during the first medical visit, the anxious patients' anxiety decreases; this may be due to the belief that the doctor treats them with increased care knowing the fears they already have [22]. A series of questionnaire tests to investigate dental anxiety had been developed and validated over the years [23]: The Childrens' Fear Survey Schedule Dental Subscale (CFSS- DS), Dental Fear Schedule Subscale (DFSS), Dental Anxiety Scale (DAS), and Modified DAS, Modified child dental anxiety scale (MCDAS), Facial Image Scale (FIS), Venham Picture Scale (VPS), Dental Fear Survey (DFS), Smiley Faces Program (SFP) and Revised SFP are only some of them.

\subsection{SCARED and its proven use}

Having an anxiety screening tool like the questionnaire designed by Birmaher et al. (1997) called SCARED - (Screen for Child Anxiety Related Disorders) [24,25] helps to 
identify the symptoms of anxiety; this test is a quick, low costs method that provides detailed information about the type of the patients' anxiety. In this study, we aimed to examine the psychometric data of this test and to validate the test's use in the Romanian population for later use in dental practice. The doctor's attitude and intervention to reduce the patient's anxiety could be adapted later to the type of anxiety demonstrated by the patient who completed the questionnaire.

The SCARED test has undergone various evaluations and changes over time and the items' number has been reduced to 38; it has two versions, for parents and children $[25,26]$. One scale asks parents questions about their child, and the other scale asks directly the child the same questions. These items evaluated five types of anxiety, according to the DSM-IV classification [27], and had 5 large subscales: generalized anxiety, social anxiety, panic disorders, separation anxiety, and school avoidance. With the apparition of DSM-V, school anxiety no longer appears among the types of anxiety, but the test remains useful because the four sub-scales are valid and have adequate psychometric values [28]. In the 1997 publication [24] the test had an average agreement between the parent-child assessment (correlation coefficients of $0.37-0.62$ ) so, in our study we analyzed and used only the items addressed to children and adolescents with good internal consistency $(\mathrm{a}=0.7-0.9)$, also test-retest fidelity had high scores $(\mathrm{p}=0.6$ 0.9). The test was also analyzed with the Childhood Behavior Checklist (Achenbach and Edelbrock, 1983) [29] and STAIC (Spielberger, 1973) [30], in which its validity was demonstrated. In the final version, the 41-items one, Birmaher et.al. (1999) [26] added 3 more items to assess social phobia. The test was designed for the English population, and over time was translated and validated on the Dutch population (Hale et al, 2005) [31], German (Weitkamp et al., 2010) [32], Italian (Crocetti et al., 2009; Ogliari et al. al., 2006) [33,34], Belgian (Muris et al., 2002) [35], Spanish (Vigil-Colet et al., 2008) [36], Chinese (Su et al., 2008) [37], and South Africa (Muris et al., 2006) [38].The original instrument and other cross-cultural studies demonstrated good internal consistency ( $\alpha$ from .74 to .93) and optimal test-retest reliability (from .70 to .90).

SCARED test items are short and simple sentences, and subjects are asked to choose based on the mood of the last three months whether the statement is "Untrue or rarely true", "Somewhat true or sometimes true" or "Very true or very often". These answers represent a score from 0 to 2 . Each item represents one of the five subscales that the test was designed to analyze. There are 13 items for checking panic symptoms (eg. when you scare me, it's hard for me to breathe), 9 items for generalized anxiety (eg I'm worried things won't work out the way I want.), 8 items for anxiety separation (eg if I sleep somewhere other than at home, I feel scared), 7 items for social anxiety (I feel anxious when I'm with people I don't know well.) and 4 items for school phobia (I have a stomach ache at school.) The higher the scores, the more severe are the anxiety symptoms. The test's authors set a minimum score of 25 [25], above which an anxiety disorder can be assumed. Because this test is just an anxiety screening tool, the authors also recommend a clinical interview to make a final diagnosis.

Usually, anxious children are not observed properly in the general population, in school, home, or social settings because they are culturally considered to be "good kids", compliant, submissive, they do not create "problems" for adults to notice them. SCARED-C is one of the best screening instruments for anxiety disorders according to DSM-IV criteria with cross-culturally good validity and reliability, as samples from the USA, Europe, Africa, and China have proved in a meta-analytical study [39].

The test is useful in the general and clinical population, for children between the ages of 8 and 18 [31,38]. The biggest advantage is the free accessibility of the test and the fact that the administration does not exceed more than 10 minutes.

\subsection{Study hypotheses}


1. To our knowledge, this is the first systematic study on psychometric properties of screening instrument SCARED-C in Romania. The study hypotheses were:Mean and standard deviation norms in our Romanian sample are similar to other studies in different countries;

2. The factor structure of Scared in the Romanian sample is similar to the original study of Birmaher et al. (1997) [24]. Confirmatory factor analysis will prove a better fit for the five-factor model of anxiety explained by SCARED than for the one factor model;

3. Girls have higher levels of anxiety than boys in the Romanian version of SCARED; by using the same instrument, early adolescents and middle adolescents demonstrate higher anxiety values than older adolescents;

4. The Romanion version of SCARED has good internal consistency and testretest reliability for further use in research and clinical practice.

\section{MATERIAL AND METHOD}

\subsection{Participants}

The present study included 477 children and adolescents from different primary, junior high, and high schools of two public schools in Târgu Mureș, a town situated in the Central region of Romania. All minor participants had the informed consent of one of the parents regarding participation in the study. From the total sample, $51.5 \%$ were boys ( 244 children) and 48.9 were girls (210 children). Participants were children aged 8 to $19(\mathrm{M}=14.2, \mathrm{SD}=2.8)$, divided into three age groups: 56 early adolescents, aged 8-10 (11.7\%), 160 middle adolescents - 11-14 years old (33.5\%) and 261 older adolescents, 1519 years old $(54,7 \%)$. The nationality of the children was mostly Romanian $(74.8 \%)$, Hungarian $(3.45 \%)$, and $21.8 \%$ undeclared. According to their residence, 371 participants declared urban $(77.8 \%), 57$ rural $(11.9 \%)$ and $106(22.2 \%)$ unanswered. From the total sample, only 84 children could be re-tested with the same instrument one month later, to determine the test-retest reliability of the Romanian version of the SCARED-C scale.

\subsection{Procedure}

The pupils of the study group completed the SCARED-C (Screen for Child Anxiety Related Emotional Disorders), a children's version designed by Birmaher et al. [24]. Two of the authors were trained in the application of this questionnaire to pupils so that any influences in completing the answers by the participants were eliminated. Two public schools permitted the test application, and some of the classes agreed with the informed consent. The confidentiality and anonymity for participation were assured. The tests were administered during classes and with the participation of teachers.

For the primary classes, a few additional comments and explanations were necessary, and two of us helped even with this issue. The scale was completed by all participants individually, with group instruction for all. The duration for completion was about 20 minutes in total. Students who were absent on the day of testing were not assessed. All students received the following written instructions: "Below is a list of sentences that describe how people feel. Read each phrase and decide if it is "Not True or Hardly Ever True" or "Somewhat True or Sometimes True" or "Very True or Often True" for you. Then, for each sentence, fill in one circle that corresponds to the response that seems to describe you for the last 3 months. There are no right or wrong answers. Honestly, say how you generally feel. Please do not skip any statements." These instructions were printed above each questionnaire. After completion, the authors collected the scales and gave them back for research.

\subsection{Measure}


The authors selected SCARED-C (41-items), elaborated by Birmaher et al. [24].

The Romanian version of the SCARED test adaptation procedure consisted of several phases. First, after asking for permission from the authors, the SCARED-C screening instrument was translated into the Romanian language then translated back into English by two different experts in both English and Psychology. Both versions were compared, and inconsistencies were resolved. The translation aimed at finding in Romanian the conceptual equivalents of words or phrases, not the word-for-word version. Usage of technical or overly scientific terms and academic language was avoided. Given that the test was also administered to adolescents a common, colloquial language was used. The retroversion was done by a translator who did not know the SCARED test and finally, we got the version used for our study. During the second phase, the SCARED-C screening tool was used in this pilot study, to determine the initial psychometric properties of the Romanian version.

\subsection{Data analysis}

Demographics of the participants were analyzed using means, standard deviation, and frequencies, using SPSS 19.0. Skewness and kurtosis indices were calculated to determine the normality of the variable's distribution. Based on the cut-off scores of Birmaher Romanian norms for anxiety and non-anxiety groups we explored the differences between the two tests, t-test and MANOVA in SPSS 19.0. Construct validity of SCARED-C was examined by using two Confirmatory Factorial Analysis (CFA): onefactor model and five-correlated factor model. The one-factor model had the latent construct anxiety, while the five-factor model had the latent construct of the five types of anxiety disorders included in the theoretical model of 41-item SCARED-C version: Panic Disorder/Somatic Symptoms, Generalized Anxiety Disorder, Separation Anxiety, Social Anxiety, and Significant School Avoidance. CFA was calculated using Lavaan on a free website application named CBDI (Classical and Bayesian Development Instrument Beta Version) developed by Karanevich et al. (2015) [40]. Because the SCARED-C is rated on a three-point Likert scale, we used a diagonally weighted least squares (DWLS) estimator rather than using the maximum likelihood (ML) estimator in the CFA. The following cutoffs in different fit indices were used to determine an acceptable model: normed chi-square (i.e., chi-square value divided by the degrees of freedom) $<3$, comparative fit index (CFI) $>0.85$ and Tucker-Lewis index (TLI) $>0.90$, root mean square of error approximation (RMSEA) and standardized root mean square residual (SRMR) $<0.08$. The model with best-fit results indices was then explored for sex and age differences. To examine the reliability and internal consistency of the scale, the Alpha Cronbach coefficient was calculated and Pearson correlation coefficients on test-retest administration, using SPSS 19.0.

\section{RESULTS}

\subsection{The Romanian SCARED norms (Hypothesis1)}

Descriptive statistics were conducted to explore the normality of distribution. Table 1 presents means, standard deviations and skewness and kurtosis indices for the overall score and subscales of Romanian version of SCARED-C. The results showed an asymmetrical distribution, with skewness and kurtosis indices higher than critical value 1 for total score and two subscales (PD and SA). One reason for this asymmetry may be the existence of two sub-groups in our sample, anxious and non-anxious children and adolescents. This hypothesis was explored further in Table 2, where descriptives and ttest of mean differences are presented.

Table 1. Demographics Means, standard deviations and skewness and kurtosis of the anxiety subscales. 


\begin{tabular}{ccccc}
\hline SCARED & Mean & Standard deviation & Skewness & Kurtosis \\
\hline Total score (TS) & 19.1 & 12.2 & 1.0 & 1.1 \\
Panic disorder (PD) & 4.4 & 4.1 & 1.8 & 4.0 \\
Generalized anxiety & 4.8 & 3.7 & 0.8 & 0.1 \\
disorder (GAD) & & & & \\
Separation Anxiety & 3.5 & 2.8 & 0.9 & 0.7 \\
(SAD) & 4.7 & 3.3 & 0.4 & -0.5 \\
Social Anxiety (SC) & 1.6 & 1.7 & 1.3 & 1.7 \\
School Avoidance (SA) & & & \\
\hline
\end{tabular}

Birmaher et al (1997) specified a cut-off point of 25 for identifying clinical anxiety scores on SCARED (overall score). In our sample of 477 children and adolescents, based on cut-off score of 25 we could identify 355 people (74.4\%) with normal anxiety and 122 children $(25.6 \%)$ with clinical anxiety, according to SCARED screening instrument. Table 2 shows significant discrepancies between mean values of anxious and non-anxious groups and $\mathrm{t}$-values on overall score and its subscales. These differences are statistically significant at $\mathrm{p}<.01$ for both the overall score and the SCARED subscales; School Avoidance (SA) was the only subscale significant at $p<.05$. We can conclude that: a) initial asymmetry of distribution is due to these sub-groups and b) the Romanian version of SCARED is a sensitive instrument and can discriminate between anxious and non-anxious children even in a community sample (normal population).

The means and standard deviation obtained in the Romanian sample are quite close to the values identified by Birmaher et.al. (1999) [26] in both anxious and non-anxious groups. Similar results have been obtained in the Italian sample (Crocetti et al., 2009; Ogliari et al., 2006) [33,34] and the Dutch sample (Hale et al., 2005) [31]. Overall, as proved by the meta-analytical study conducted by Hale et al., 2011 [39], there is good support for using the instrument cross-culturally in the mental health practice. Our study fills the gap of missing Romanian norms by showing similar values with other European samples. Hypothesis 1 is confirmed.

Table 2. Means, standard deviations and t-test for anxious and non-anxious children according to Romanian version of SCARED-C.

\begin{tabular}{|c|c|c|c|c|c|c|}
\hline \multirow[t]{2}{*}{ SCARED } & \multicolumn{2}{|c|}{ Mean } & \multicolumn{2}{|c|}{ Standard deviation } & \multirow[b]{2}{*}{ t-test } & \multirow[b]{2}{*}{ p-value } \\
\hline & $\begin{array}{c}\text { Non-anxious } \\
\text { group }\end{array}$ & Anxious group & Non-anxious group & Anxious group & & \\
\hline Total score (TS) & 13.3 & 35.7 & 6.5 & 9.1 & -24.9 & .00 \\
\hline Panic disorder (PD) & 2.7 & 9.0 & 2.0 & 4.9 & -13.5 & .00 \\
\hline $\begin{array}{l}\text { Generalized anxiety } \\
\text { disorder (GAD) }\end{array}$ & 3.2 & 9.4 & 2.4 & 3.1 & -20.0 & .00 \\
\hline $\begin{array}{c}\text { Separation Anxiety } \\
\text { (SAD) }\end{array}$ & 2.5 & 6.4 & 1.9 & 2.9 & -13.7 & .00 \\
\hline Social Anxiety (SC) & 3.6 & 7.9 & 2.7 & 2.8 & -14.7 & .00 \\
\hline School Avoidance (SA) & 1.2 & 2.8 & 1.4 & 1.9 & -8.6 & .03 \\
\hline
\end{tabular}


The factor structure of the Romanian version of SCARED-C was examined by means of Confirmatory Factor Analysis (CFA). As it can be seen from Table 3, the onefactor model has a bad fit (chi-square normed higher than 3), CFI, TLI and RMSEA indices show an acceptable fit and SRMR indicates a bad fit for the overall sample.

The five-factor model had a significantly better fit than one-factor model, as the chisquare test shows (a value of 1.90, less than critical value of $3, \mathrm{p}<.01$ ). The five-factor model of the overall sample corresponds to the theoretical model proposed by Birmaher et al. (1997) [24] and include the following factors: Panic disorder (PD) /Somatic Symptoms (SS); Generalized Anxiety Disorder (GAD); Separation Anxiety (SAD); Social Anxiety (SC); School Avoidance (SA). All model fit indices have the critical values going from acceptable fit (SRMR) to good fit (CFI, TLI, RMSEA) and very good fit (normed chisquare). Hypothesis 2 is confirmed.

Table 3. Model fit indices for one-factor model and the five-factor model of the Romanian version of SCARED (N=477).

\begin{tabular}{|c|c|c|c|c|c|c|}
\hline & $\mathbf{N}$ & Chi square & CFI & TLI & RMSEA & SRMR \\
\hline One-factor model & 477 & $\begin{array}{c}3.41 \\
p<0.01\end{array}$ & 0.930 & 0.926 & $\begin{array}{c}0.071 \\
p=0.00\end{array}$ & 0.104 \\
\hline \multicolumn{7}{|l|}{ Five-factor model } \\
\hline Total sample & 477 & $\begin{array}{c}1.90 \\
p<0.001\end{array}$ & 0.974 & 0.972 & $\begin{array}{c}0.044 \\
p=0.99\end{array}$ & 0.082 \\
\hline Boys & 267 & $\begin{array}{c}1.44 \\
\mathrm{P}<0.001\end{array}$ & 0.972 & 0.970 & $\begin{array}{c}0.041 \\
\mathrm{P}=0.99\end{array}$ & 0.104 \\
\hline Girls & 133 & $\begin{array}{c}1.42 \\
\mathrm{P}<0.001\end{array}$ & 0.976 & 0.975 & $\begin{array}{c}0.045 \\
\mathrm{P}=0.90\end{array}$ & 0.099 \\
\hline Early adolescents & 56 & $\begin{array}{c}1.23 \\
\mathrm{P}<.0 .001\end{array}$ & 0.967 & 0.965 & $\begin{array}{c}0.065 \\
\mathrm{P}=0.05\end{array}$ & 0.171 \\
\hline Middle adolescents & 160 & $\begin{array}{c}1.09 \\
\mathrm{P}<0.05\end{array}$ & 0.994 & 0.993 & $\begin{array}{c}0.024 \\
\mathrm{P}=1.00\end{array}$ & 0.103 \\
\hline Older adolescents & 261 & $\begin{array}{c}1.44 \\
\mathrm{P}<0.001\end{array}$ & 0.975 & 0.973 & $\begin{array}{c}0.041 \\
\mathrm{P}=0.997\end{array}$ & 0.106 \\
\hline
\end{tabular}

Note: N: number of participants; CFI: Comparative Fit Index; TLI: Tucker-Lewis Index; RMSEA: Root Mean Square Residual; SRMR: Standardized Root Mean Square.

The factor loadings and Pearson item-total correlation are presented in Table 4. Factor $1(\mathrm{PD})$ include 13 items, with values ranging from .40 for item 19 "I get shaky" to highest level of .88 for item 6 "When I get frightened, I feel like passing out”. The itemtotal correlation values for this factor are medium, going from .36 for item 34 to a highest level of .56 for item 24 .

Factor 2 (GAD) is loaded with 9 items, the lowest value of factor loading being .54 „I worry about other people liking me" (item 5) to highest level of .76 for item 23- "I am a worrier." The item-total correlations for this factor are ranging from .39 to .52 .

Factor 3 (SAD) has 8 items, with saturation values ranging from .42 for item 22 "I don't like to be away from my family." to value of .72 (item 16) "I have nightmares about something bad happening to my parents.". Item-total correlations are ranging from .29 to .47 , for the same items.

Factor 4 (SC) has 7 items, factor loading ranging from .41 (item 3) "I don't like to be with people I don't know well." to highest value of .75 (item 40) "I feel nervous when I am going to parties, dances, or any place where there will be people that I don't know well." Item-total correlations for these items are between .24-.50 
Factor 5 (SA) has 4 items with factor loadings varying from .53 (item 2)" I get headaches when I am at school. "to .78 (item 36) "I am scared to go to school.". Pearson item-total correlations for this factor vary between .27 and .39 .

Table 4. Factor loading and factor internal consistency ( $\mathrm{N}=477)$.

\begin{tabular}{|c|c|c|c|c|c|c|}
\hline SCARED item & $\begin{array}{l}\text { Panic } \\
\text { Disorder }\end{array}$ & $\begin{array}{c}\text { Generali- } \\
\text { zed } \\
\text { Anxiety } \\
\text { Disorder }\end{array}$ & $\begin{array}{l}\text { Separa- } \\
\text { tion } \\
\text { Anxiety }\end{array}$ & $\begin{array}{c}\text { Social } \\
\text { Anxi-ety }\end{array}$ & $\begin{array}{c}\text { School } \\
\text { Avoidanc } \\
\text { e }\end{array}$ & $\begin{array}{c}\text { Pearson } \\
\text { Item-total } \\
\text { correlation }\end{array}$ \\
\hline S1 When I feel frightened, it is hard to breathe & 0.62 & & & & & .44 \\
\hline S6 When I get frightened, I feel like passing out. & 0.88 & & & & & .46 \\
\hline S9 People tell me that I look nervous. & 0.60 & & & & & .41 \\
\hline $\begin{array}{l}\text { S12 When I get frightened, I feel like I am going } \\
\text { crazy. }\end{array}$ & 0.73 & & & & & .52 \\
\hline $\begin{array}{c}\text { S15 When I get frightened, I feel like things are not } \\
\text { real. }\end{array}$ & 0.60 & & & & & .42 \\
\hline S18 When I get frightened, my heart beats fast. & 0.40 & & & & & .31 \\
\hline S19 I get shaky. & 0.67 & & & & & .52 \\
\hline S22 When I get frightened, I sweat a lot. & 0.66 & & & & & .47 \\
\hline S24 I get really frightened for no reason at all. & 0.81 & & & & & .56 \\
\hline S27 When I get frightened, I feel like I am choking. & 0.84 & & & & & .49 \\
\hline S30 I am afraid of having anxiety (or panic) attacks. & 0.75 & & & & & .51 \\
\hline S34 When I get frightened, I feel like throwing up. & 0.73 & & & & & .36 \\
\hline S38 When I get frightened, I feel dizzy. & 0.79 & & & & & .51 \\
\hline S5 I worry about other people liking me. & & 0.54 & & & & .39 \\
\hline S7 I am nervous. & & 0.58 & & & & .43 \\
\hline S14 I worry about being as good as other kids. & & 0.68 & & & & .51 \\
\hline S21 I worry about things working out for me. & & 0.65 & & & & .50 \\
\hline S23 I am a worrier. & & 0.76 & & & & .54 \\
\hline S28 People tell me that I worry too much. & & 0.68 & & & & .48 \\
\hline $\begin{array}{c}\text { S33 I worry about what is going to happen in the } \\
\text { future. }\end{array}$ & & 0.70 & & & & .52 \\
\hline S35 I worry about how well I do things. & & 0.67 & & & & .49 \\
\hline $\begin{array}{l}\text { S37 I worry about things that have already } \\
\text { happened. }\end{array}$ & & 0.69 & & & & .52 \\
\hline S4 I get scared if I sleep away from home. & & & 0.64 & & & .40 \\
\hline S8 I follow my mother or father wherever they go. & & & 0.59 & & & .38 \\
\hline S13 I worry about sleeping alone. & & & 0.71 & & & .39 \\
\hline $\begin{array}{l}\text { S16 I have nightmares about something bad } \\
\text { happening to my parents. }\end{array}$ & & & 0.72 & & & .47 \\
\hline $\begin{array}{l}\text { S20 I have nightmares about something bad } \\
\text { happening to me. }\end{array}$ & & & 0.61 & & & .43 \\
\hline S25 I am afraid to be alone in the house. & & & 0.70 & & & .38 \\
\hline S29 I don't like to be away from my family. & & & 0.42 & & & .29 \\
\hline $\begin{array}{l}\text { S31 I worry that something bad might happen to } \\
\text { my parents. }\end{array}$ & & & 0.55 & & & .38 \\
\hline S3 I don't like to be with people I don't know well. & & & & 0.41 & & .24 \\
\hline S10 I feel nervous with people I don't know well. & & & & 0.68 & & .44 \\
\hline $\begin{array}{l}\text { S26 It is hard for me to talk to people I don't know } \\
\text { well. }\end{array}$ & & & & 0.72 & & .47 \\
\hline
\end{tabular}


S32 I feel shy with people I don't know well. S39 I feel nervous when I am with other children or adults and I have to do something while they watch me (for example: read aloud, speak, play a game,

$$
\text { play a sport). }
$$

S40 I feel nervous when I am going to parties, dances, or any place where there will be people that I don't know well.

$$
0.74
$$

S41 I am shy.

S2 I get headaches when I am at school.

S11 I get stomachaches at school.

S17 I worry about going to school.

S36 I am scared to go to school.
.47

0.75

.50

0.71

$\begin{array}{ll} & .45 \\ 0.53 & .27 \\ 0.76 & .39 \\ 0.74 & .36 \\ 0.78 & .30\end{array}$

\subsection{Sex and age difference within the Romanian sample (Hypothesis 3)}

MANOVA results indicated that, using Wilkis-Lambda criteria, the correlated dependent variables of SCARED-C (anxiety subscales) are significantly influenced by sex $\left(F(454)=12.2, p<.001, \eta^{2}=.12\right)$ and age $\left(F(474)=15.2, p<.001, \eta^{2}=.13\right)$ but not significantly influenced by their interaction (sex and age): $F(453)=.88, p=.54, \eta^{2}=.01$.

\subsubsection{Sex differences}

Girls were found to score significantly higher than boys in overall score $\left(\mathrm{F}(454)=34.8, \mathrm{p}<.001, \eta^{2}=.07\right)$, on Panic Disorder $\left(\mathrm{F}(454)=20.6, \mathrm{p}<.001, \eta^{2}=.04\right)$, on Generalised Anxiety Disorder $\left(\mathrm{F}(454)=52.1, \mathrm{p}<.001, \eta^{2}=.10\right)$, on Social Anxiety Disorder $\left(\mathrm{F}(454)=20.5, \mathrm{p}<.001, \eta^{2}=.04\right)$ and Separation Anxiety $\left(\mathrm{F}(454)=11.0, \mathrm{p}<.001, \eta^{2}=.02\right)$. No significant difference was found for School Avoidance $\left(F(454)=.29, p>.05, \eta^{2}=.00\right)$. Results are shown in Table 5 below.

\subsubsection{Age differences}

It seems that anxiety decreases with age in our group. MANOVA results and Dunnett T3 post-hoc tests showed that the first subgroup (8-10 years) scores significantly higher than older group (15-19 years) but not than the middle one (11-14 years), on overall score $\left(F(472)=17.5, \mathrm{p}<.001, \eta^{2}=.06\right)$, on Panic Disorder $\left(F(454)=20.6, p<.001, \eta^{2}\right.$ $=.04$ ) and Social Anxiety Disorder $\left(\mathrm{F}(472)=10.4, \mathrm{p}<.001, \eta^{2}=.04\right)$. There is no relevant impact of age on Generalised Anxiety Disorder or School Avoidance (Table 5).

The results showed higher anxiety values for girls than boys, and a decrease of anxiety with age; thus, Hypothesis 3 is confirmed.

\begin{tabular}{|c|c|c|c|c|c|c|c|c|c|}
\hline & & Gender & & Effect size & & Age & & & $\overline{\text { Effect size }}$ \\
\hline & $\begin{array}{c}\text { Boys } \\
(\mathrm{N}=244)\end{array}$ & $\begin{array}{c}\text { Girls } \\
(\mathrm{N}=210)\end{array}$ & $\mathbf{F}$ & $\begin{array}{c}\text { Partial Eta } \\
\text { Square }\end{array}$ & $8-10$ & $11-14$ & $15-19$ & $\mathrm{~F}$ & $\begin{array}{c}\text { Partial Eta } \\
\text { Square }\end{array}$ \\
\hline Total score & $16.0 \pm 10.91$ & $22.52 \pm 12.66$ & 34.8 & $\begin{array}{c}.07 \\
\text { Medium }\end{array}$ & $24.78 \pm 13.30$ & $21.66 \pm 13.35$ & $16.31 \pm 10.35$ & 17.5 & $\begin{array}{c}.07 \\
\text { medium }\end{array}$ \\
\hline $\begin{array}{c}\text { Panic } \\
\text { Disorder/Somati } \\
\text { c Symptoms }\end{array}$ & $3.59 \pm 3.50$ & $5.33 \pm 4.67$ & 20.6 & $\begin{array}{c}.04 \\
\text { small }\end{array}$ & $6.33 \pm 5.27$ & $5.29 \pm 4.56$ & $3.44 \pm 3.22$ & 18.1 & $\begin{array}{c}.05 \\
\text { medium }\end{array}$ \\
\hline $\begin{array}{c}\text { Generalised } \\
\text { Anxiety } \\
\text { Disorder }\end{array}$ & $3.69 \pm 3.20$ & $6.12 \pm 3.59$ & 52.1 & $\begin{array}{c}.10 \\
\text { Medium }\end{array}$ & $5.33 \pm 4.01$ & $4.93 \pm 4.00$ & $4.67 \pm 3.57$ & .78 & $\begin{array}{c}.00 \\
\text { small }\end{array}$ \\
\hline
\end{tabular}

Table 5. Gender and age differences and effect size (MANOVA results). 


\begin{tabular}{|c|c|c|c|c|c|c|c|c|c|}
\hline $\begin{array}{c}\text { Separation } \\
\text { Anxiety }\end{array}$ & $3.07 \pm 2.64$ & $3.94 \pm 2.89$ & 11.0 & $\begin{array}{c}.02 \\
\text { small }\end{array}$ & $5.92 \pm 3.15$ & $4.33 \pm 2.90$ & $2.49 \pm 2.12$ & 54.3 & $\begin{array}{c}.18 \\
\text { large }\end{array}$ \\
\hline Social Anxiety & $4.05 \pm 3.24$ & $5,45 \pm 3.31$ & 20.5 & $\begin{array}{c}.04 \\
\text { small }\end{array}$ & $5.23 \pm 2.80$ & $5.55 \pm 3.57$ & $4.09 \pm 3.21$ & 10.4 & $\begin{array}{c}.04 \\
\text { medium }\end{array}$ \\
\hline $\begin{array}{c}\text { School } \\
\text { Avoidance }\end{array}$ & $1.58 \pm 1.88$ & $1.67 \pm 1.66$ & .29 & $\begin{array}{c}.00 \\
\text { small }\end{array}$ & $1.94 \pm 1.93$ & $1.54 \pm 1.66$ & $1.60 \pm 1.73$ & 1.1 & $\begin{array}{c}.00 \\
\text { small }\end{array}$ \\
\hline
\end{tabular}

\subsection{Internal consistency and test-retest reliability of Romanian SCARED version (Hypothesis 4)}

The Cronbach's alpha internal consistency coefficients were calculated for overall score and distinct subscales. For the overall score $\alpha$ was $.91, .83$ for panic/somatic anxiety $(\mathrm{PN})$ subscale, .81 for generalized anxiety (GD), .70 for separation anxiety (SP), .78 for social anxiety disorder (SC) and .63 for school significant avoidance (SH). At time of retesting $(\mathrm{N}=88)$ internal consistency was .90 for the total scale, .81 for PN and GD, .66 for SP, .83 for SC and .67 for SH. Both administrations of Romanian version of SCARED demonstrate a very good internal consistency for this instrument. The results obtained are consistent with the results of Birmaher et al. (1997).

The consistency of the Romanian version of SCARED over time was explored using test-retest reliability for overall general score and subscales, based on two evaluations of the same instrument at one-month interval. Test-retest correlations took values between 0.47 and 0.70 (Table 6). The test-retest reliability in our Romanian sample was quite modest because it was difficult to find the same children and adolescents for retesting in schools, after one month. Future studies can fix this problem with more accurate design. The smallest coefficients were for Separation Anxiety (.53) that decreases in adolescence and for school avoidance (.47), issue already discussed earlier as having a weaker contribution to the total score of SCARED. Results are presented in Table 6. Social anxiety (.70) and total score (.70) were the highest in consistency over time, but still al the lower limit of a good consistency measure. The Romanian Scared version showed good consistency and test-retest reliability, proving to be a useful tool for research and practice. Our fourth hypothesis is confirmed.

Table 6. Alpha Cronbach total and subscales and test-retest reliability.

\begin{tabular}{|c|c|c|c|c|c|}
\hline SCARED & $\begin{array}{c}\text { Alpha Cronbach } \\
\text { coefficient } \\
\text { Test1 }(\mathrm{n}=477)\end{array}$ & $\begin{array}{c}\text { Alpha Cronbach } \\
\text { coefficient } \\
\text { Test } 2(n=88)\end{array}$ & Test $1(\mathrm{~m} \pm \mathrm{sd})$ & Test $2(\mathrm{~m} \pm \mathrm{sd})$ & $\mathbf{r}_{12}$ \\
\hline Total score (TS) & 0.91 & .90 & $19.10 \pm 12.20$ & $14.77 \pm 10.39$ & $.70^{* *}$ \\
\hline Panic disorder (PN) & 0.83 & .81 & $4.40 \pm 4.13$ & $3.23 \pm 3.50$ & $.63^{* *}$ \\
\hline $\begin{array}{l}\text { Generalized anxiety } \\
\text { (GD) }\end{array}$ & 0.81 & .81 & $4.84 \pm 3.77$ & $3.70 \pm 3.37$ & $.64^{* *}$ \\
\hline Separation Anxiety (SP) & 0.70 & .66 & $3.51 \pm 2.81$ & $2.08 \pm 2.10$ & $.53^{* *}$ \\
\hline Social Anxiety (SC) & 0.78 & .78 & $4.72 \pm 3.36$ & $3.94 \pm 3.13$ & $.70^{* *}$ \\
\hline School avoidance (SH) & 0.63 & .63 & $1.62 \pm 1.73$ & $1.65 \pm 1.77$ & $.47^{* *}$ \\
\hline
\end{tabular}

\section{DISCUSSIONS}

SCARED anxiety questionnaire has proven to be a tool with a high level of fidelity and validity in assessing anxiety symptoms in the Romanian population aged between 8 and 18. By using it we can prevent the occurrence of anxiety disorders that can lead to other disorders that disrupt the daily life of children and may cause behavioral problems in difficult situations like the meeting with the dentist. Through these anxiety 
assessments and studies, mental health programs can be developed to educate both children and their parents on how to cope with stressful situations that cause anxiety, monitor symptoms, and learn coping methods to have a healthy and balanced living.

By using this questionnaire, dentists can much easily determine the type of anxiety of minor patients in the dental office before any intervention. Depending on the type of anxiety demonstrated, they may perform specific psychological interventions to make dental treatment possible or may adapt their attitude when facing minor patients and their parents.

The test's results suggest that in the case of children aged 8-10 years separation anxiety has the highest values in the studied group. Aminabadi et al. [41] provided that the child's behavior confronting dental anxiety is positively correlated to the mother's emotional intelligence; authoritarian parenting style was found predominantly in mothers with high levels of emotional intelligence. They found significant correlations between authoritarian parenting style and separation anxiety. The mother's emotional intelligence may influence the child's ability to cope with stressful conditions such as seeing the dentist. This means that by influencing the authoritarian style of the parent we may reduce the separation anxiety.

The conclusion would be that, in the case of a patient with a high score in the SCARED test on elements related to separation anxiety, the dentist will have to allow the mother to enter the office together with the child; she will hold his left hand during the dental intervention or will remain to the left or in front of the little patient with whom she will keep eye contact meant to encourage him and ensure a sense of safety. At the same time, we will advise the mother not to act through an excess of authority so that the child behaves appropriately; this is the responsibility of the medical team in which the most important role is played by the doctor.

At this age children are still dependent on parental approval which they are almost always trying to get, avoiding punishment or quarrel in case of failure or disobedience. Therefore, the influence of the parents and especially of the mother is an important factor for the success of the pedodontic or orthodontic treatment.

Our study showed that social anxiety is higher in adolescents. The fear of negative evaluation of others and the self-focused attention maintain social anxiety. The social integration of the adolescent depends on the projection of the self-image and his selfesteem. It has been recognized that the morphology of the dentofacial region significantly contributes to the overall face appearance [42]. Here comes the huge role that orthodontics has in improving facial appearance. Children with a normal dental arrangement are perceived by others of their age and adults as more handsome, smarter, desirable as friends, even with superior mental qualities, and less prone to aggressive behavior [42]. On the other hand, de Jong showed the role of a negative self-image and a low self-esteem in social anxiety [43]. People with social anxiety are also characterized by a difference between the perception of self and others, this tendency to discredit themselves being a main element of social anxiety. In these situations the doctor will tactfully try to communicate better with the patient, creating a relationship based on trust and friendship. They also may feel vulnerable after traumatic dental experiences during childhood. The communication is facilitated by the fact that teenagers see dentists as professionally and materially independent people and this impresses them positively.

Particular situations are children with selective mutism which are very difficult patients; working with them is extremely hard to achieve and requires several accommodation sessions with the environment of the dental office, with the dentist and the support staff. The reason for this pathology is complex and controversial. It is unclear whether children with selective mutism could not speak because of the overwhelming anxiety or whether withholding speech functions is an avoidance mechanism. Psychophysiological measures indicated that children with selective 
mutism experienced less arousal than other children during social interaction tasks; so, the lack of speech may be an avoidance mechanism [44].

Selective mutism can have a complex etiology, involving genetic, environmental, temperament, and neurodevelopmental factors [45]. Treatment may include cognitive, behavioral therapy, or pharmacotherapy. Commonly, dentists are not trained to deal with this type of patient, even if knowledge about the diagnosis and intervention techniques in these cases are crucial. For children with selective mutism, dental visits could be a challenge [45]. Each case is unique because the causes of behavioral deviance are variable. A child who assists a dentist for a dental emergency, treatment, or routine examination may not yet be diagnosed with selective mutism so, further knowledge of the condition using the SCARED-C scale could be a tool used for a presumptive diagnosis and for choosing the correct intervention to make collaboration possible. The dental team should be aware of the possible therapy the child has already received and work with these principles during dental programs. Knowing if the child has other phobias or anxiety symptoms can help; simple strategies like asking the parent how to communicate with the little patient or understanding what makes the child feel at ease can be very helpful to establish an approach [45].

In our study, girls scored significantly higher than boys in the overall Scared-C scored. The girls scored significantly higher on panic disorder, generalized anxiety, social anxiety, and separation anxiety. No significant difference between the sexes was found for school avoidance. Our results are similar to those found in literature. For example, Fredrikson et al. [46] found a higher incidence of specific phobias in women than in men. Women, as compared to men, gave higher fear ratings for all objects and situations. Fear of injections decreased as a function of age in women but not in men [46]. McLean et al. [47] found that anxiety disorders are more prevalent and more disabling in women than in men. Women had higher rates of diagnosis for each of the anxiety disorders examined (generalized anxiety disorder, panic disorder, specific phobia and post-traumatic stress disorder) except for social anxiety disorder which showed no gender difference in prevalence. Halasa $S$ et al. [48] found significant differences between males and females in social anxiety and post-traumatic stress disorder, which were higher in females.

Anxiety decreases with age in our study group. The children between 8 and 10 years score significantly higher than the older group of 15-19 years but not than the middle group of 11-14 years on the overall score, on panic disorder and social anxiety disorder. There was no relevant impact of age on generalized anxiety disorder or school avoidance. Arab et al. [49] demonstrated the utility of using SCARED in a study group of Arabian children and adolescents similar in age with ours and found that boys proved a reduction of anxiety symptoms with age and girls showed stable and elevated anxiety symptoms at any investigated age group, suggesting the need of an intervention at an early age to prevent later mental health problems.

Patients with elevated values of general anxiety show higher increases in anxiety as a state, in the values of blood pressure and peripheral pulse in the dental office under stress [50]. Anxiety in children and adolescents can be reduced by using the breathing control technique and the Jacobson progressive muscle relaxation technique, both of which are effective in reducing anxiety as a condition and as a trait. Jacobson's progressive muscle relaxation technique is more effective in reducing the variables that define anxiety than the breathing control technique [50].

Several studies clearly indicate anxiety and stressful situations to be significantly involved in the initiation and maintenance of temporomandibular disorders (TMDs) [51]. These are important in the etiology of this complicated group of diseases [51]. TMDs are a multifactorial condition, which could be associated with malocclusions Class II and Class III when the myofascial pain has the higher prevalence and with psychological factors, such as anxiety [52]. TMD-related pain is more common in girls 
than in boys, concerning neuropsychological factors as women appear to be more vulnerable to stress, compared to men [53]. So, anxiety plays an important role in the pathogenesis of TMD.

The risk of bruxism also increases in general anxiety cases and particular stressful time periods. TMD and bruxism are frequently associated with orofacial pain, reduction of articular mobility, and pain even in normal mandibular movements [54,55].

There are other diseases positively correlated with anxiety, like recurrent aphthous stomatitis, oral lichen planus, and burning mouth syndrome [56,57,58]. Anxiety is closely associated with the incidence of trigeminal neuralgia essential (TN) [59,60]. General anxiety is positively correlated with dental fear and the perception of dental pain [61].

Future orthodontic patients reported higher levels of orthodontic dental anxiety than current patients. Anxiety and oral habits are associated with malocclusions $[62,63]$. The fear of trauma (dental trauma, bone trauma) also causes anxiety [64].

The co-presence of anxiety, associated or not with mental problems, causes neglect, so even small problems associated with poor oral hygiene can become serious, with possible worsening of the periodontal situation in orthodontic patients and the increase in therapy times due to lack of cooperation.

Virtual reality (VR) environments provide support to reduce the anxiety and the stress related to dental care and improve compliance with dentists. VR allows the patients' relaxation and distraction by giving the feeling of a more pleasant location, without stressful elements. VR may provide a possible alternative treatment for dental anxiety and phobia $[65,66]$.

A clinical protocol for approaching anxious patients by using computer software based on anxiety values determined with the SCARED-C questionnaire could be a useful working tool that would be integrated into pediatric dentistry offices [67].

After validation by the present study, we intend to use this questionnaire in our practical activity to reduce anxiety and to collaborate with the patient according to the determined anxiety type. It will be the subject of another study that will describe the anxiety changes after psychological interventions.

The value of our study is, as far as we know, that it is the first validation of the SCARED-C Scale for the Romanian population. The limitation of our study is the small number of subjects who could be retested due to pandemic conditions that restricted the students' access to schools because of the high infection rate with the Covid-19 virus.

\section{CONCLUSION}

The Romanian version of SCARED-C demonstrated a good internal consistency and proved to be a sensitive psychometric instrument to discriminate between anxious and non-anxious children . Girls scored significantly higher than boys on the overall score, on panic disorder, generalized anxiety, social anxiety, and separation anxiety. No significant difference between the sexes was found regarding school avoidance. The overall anxiety score decreases with age, but age has no relevant impact on generalized anxiety or school avoidance. Dentists could use this questionnaire to determine the type of anxiety of minor patients before any intervention and may adapt their attitude or perform specific psychological interventions to make the dental treatment possible.

Author Contributions: Conceptualization, B.S-M. and L.L.V.; methodology, B.S-M., M. A., and B.E.S.; software, M.A. and O.C.D.; validation, B.S-M., B.E.S., and V.L.L.; formal analysis, B.E.S.; investigation, B.S-M., M.A., A.B., and O.C.D.; resources, O.C.D.; data curation, M.A. and A.B.; writing-original draft preparation B.S-M. and A.B.; writing-review and editing, B.E.S.; visualization, O.C.D.; supervision, B.S-M., B.E.S., and V.L.L. All authors have read and agreed to the published version of the manuscript." 
Conflicts of Interest: the authors declare no conflict of interest associated with this paper.

Institutional Review Board Statement: the study was conducted according to the guidelines of the Declaration of Helsinki and approved by the Ethics Committee of SC Algocalm SRL, TârguMures, Romania, 910/06.04.2021.

Informed Consent Statement: informed consent was obtained from all subjects involved in the study and for the minor subjects, from one of the parents.

\section{REFERENCES}

1. Diercke K, Ollinger I, Bermejo JL, Stucke K, Lux CJ, Brunner M. Dental fear in children and adolescents: a comparison of forms of anxiety management practised by general and paediatric dentists. Int J Paediatr Dent. 2012 Jan;22(1):60-7. doi: 10.1111/j.1365-263X.2011.01158.x.

2. Coutinho FC, Dias GP, do Nascimento Bevilaqua MC, Gardino PF, Pimentel Rangé B, Nardi AE. Current concept of anxiety: implications from Darwin to the DSM-V for the diagnosis of generalized anxiety disorder. Expert Rev Neurother. 2010 Aug;10(8):1307-20. doi: 10.1586/ern.10.101.

3. Okun A, Stein RE, Bauman LJ, Silver EJ. Content validity of the Psychiatric Symptom Index, CES-depression Scale, and State-Trait Anxiety Inventory from the perspective of DSM-IV. Psychol Rep. 1996 Dec;79(3 Pt 1):105969. doi: 10.2466/pr0.1996.79.3.1059.

4. American Psychiatric Association. Diagnostic and Statistical Manual of Mental Disorders, 5th edition (DSM-V). Washington, DC: American Psychiatric Association (2013). doi: 10.1176/appi.books.9780890425596.

5. Bosquet M, Egeland B. The development and maintenance of anxiety symptoms from infancy through adolescence in a longitudinal sample. Dev Psychopathol. 2006 Spring; 18(2):517-50. doi: $10.1017 /$ S0954579406060275.

6. Ehrenreich JT, Santucci LC, Weiner CL. SEPARATION ANXIETY DISORDER IN YOUTH: PHENOMENOLOGY, ASSESSMENT, AND TREATMENT. Psicol Conductual. 2008;16(3):389-412. doi:10.1901/jaba.2008.16-389.

7. Seligman LD, Hovey JD, Chacon K, Ollendick TH. Dental anxiety: An understudied problem in youth. Clin Psychol Rev. 2017 Jul;55:25-40. doi: 10.1016/j.cpr.2017.04.004. Epub 2017 Apr 19.

8. Talo Yildirim T, Dundar S, Bozoglan A, Karaman T, Dildes N, Acun Kaya F, Altintas E, Oztekin F, Atas O, Alan H. Is there a relation between dental anxiety, fear and general psychological status? PeerJ. 2017 Feb 15;5:e2978. doi: $10.7717 /$ peerj.2978.

9. Nigam AG, Marwah N, Goenka P, Chaudhry A. Correlation of general anxiety and dental anxiety in children aged 3 to 5 years: A clinical survey. J Int Oral Health. 2013 Dec;5(6):18-24. Epub 2013 Dec 26.

10. Izgiç F, Akyüz G, Doğan O, Kuğu N. Social phobia among university students and its relation to self-esteem and body image. Can J Psychiatry. 2004 Sep;49(9):630-4. doi: 10.1177/070674370404900910.

11. Muammariyah, B. (2009). Social anxiety: Emotional situations, prevalence ratios, gender and age differences. Journal of the Arab Psychological Network, 21-22, 135-149.

12. Pichot P. Le DSM-III: troisième édition du manuel diagnostique et statistique des troubles mentaux de l'Association américaine de psychiatrie [DSM-III: the 3d edition of the Diagnostic and Statistical Manual of Mental Disorders from the American Psychiatric Association]. Rev Neurol (Paris). 1986;142(5):489-99. French.

13. Jefferys D. Social phobia. The most common anxiety disorder. Australian Family Physician. 1997 Sep;26(9):1061, 1064-7.

14. Crocq MA. A history of anxiety: from Hippocrates to DSM. Dialogues Clin Neurosci. 2015 Sep;17(3):319-25. doi: 10.31887/DCNS.2015.17.3/macrocq.

15. Black B, Uhde TW. Psychiatric characteristics of children with selective mutism: a pilot study. J Am Acad Child Adolesc Psychiatry. 1995 Jul;34(7):847-56. doi: 10.1097/00004583-199507000-00007.

16. Viana AG, Beidel DC, Rabian B. Selective mutism: a review and integration of the last 15 years. Clin Psychol Rev. 2009 Feb;29(1):57-67. doi: 10.1016/j.cpr.2008.09.009. Epub 2008 Sep 30.

17. Halonen H, Nissinen J, Lehtiniemi H, Salo T, Riipinen P, Miettunen J. The Association Between Dental Anxiety And Psychiatric Disorders And Symptoms: A Systematic Review. Clin Pract Epidemiol Ment Health. 2018 Aug 31;14:207-222. doi: 10.2174/1745017901814010207.

18. Locker D, Liddell A, Dempster L, Shapiro D. Age of Onset of Dental Anxiety. Journal of Dental Research. 1999;78(3):790-796. doi:10.1177/00220345990780031201.

19. Zinke, A., Hannig, C. \& Berth, H. Psychological distress and anxiety compared amongst dental patients- results of a cross-sectional study in 1549 adults. BMC Oral Health 19, 27 (2019). https://doi.org/10.1186/s12903-019-0719-3. 
20. Myers, K., \& Winters, N. C. (2002). Ten-year review of rating scales. II: Scales for internalizing disorders. Journal of American Academic Child and Adolescent Psychiatry, 41, 634-659.

21. Cocârlă E. Stomatologie pediatrică. Ed. Medicală Universitară „Iuliu Hațieganu”, Cluj-Napoca,2000,84-91.

22. Dailey $\mathrm{YM}$, Humphris GM, Lennon MA. Reducing patients' state anxiety in general dental practice: a randomized controlled trial. J Dent Res. 2002 May;81(5):319-22. doi: 10.1177/154405910208100506.

23. Porritt J, Buchanan H, Hall M, Gilchrist F, Marshman Z. Assessing children's dental anxiety: a systematic review of current measures. Community Dent Oral Epidemiol. 2013 Apr;41(2):130-42. doi: 10.1111/j.16000528.2012.00740.x. Epub 2012 Sep 12.

24. Birmaher B, Khetarpal S, Brent D, Cully M, Balach L, Kaufman J, Neer SM. The Screen for Child Anxiety Related Emotional Disorders (SCARED): scale construction and psychometric characteristics. J Am Acad Child Adolesc Psychiatry. 1997 Apr;36(4):545-53. doi: 10.1097/00004583-199704000-00018.

25. Screen for Child Anxiety Related Disorders (SCARED), Child Version and Parent Version,https://www.ohsu.edu/sites/default/files/2019-06/SCARED-form-Parent-and Child-version.pdf, seen on 24 March 2018.

26. Birmaher B, Brent DA, Chiappetta L, Bridge J, Monga S, Baugher M. Psychometric properties of the Screen for Child Anxiety Related Emotional Disorders (SCARED): a replication study. J Am Acad Child Adolesc Psychiatry. 1999 Oct;38(10):1230-6. doi: 10.1097/00004583-199910000-00011.

27. American Psychiatric Association (1994) Diagnostic and Statistical Manual of Mental Disorders (4rd edn) (DSMIV). Washington, D. C.: American Psychiatric Press.

28. Hale Iii WW, Raaijmakers QA, van Hoof A, Meeus WH. Improving Screening Cut-Off Scores for DSM-5 Adolescent Anxiety Disorder Symptom Dimensions with the Screen for Child Anxiety Related Emotional Disorders. Psychiatry J. 2014;2014:517527. doi: 10.1155/2014/517527. Epub 2014 Jan 29.

29. Lohr WD, Daniels K, Wiemken T, Williams PG, Kelley RR, Kuravackel G, Sears L. The Screen for Child AnxietyRelated Emotional Disorders Is Sensitive but Not Specific in Identifying Anxiety in Children with HighFunctioning Autism Spectrum Disorder: A Pilot Comparison to the Achenbach System of Empirically Based Assessment Scales. Front Psychiatry. 2017 Aug 2;8:138. doi: 10.3389/fpsyt.2017.00138.

30. Monga S, Birmaher B, Chiappetta L, Brent D, Kaufman J, Bridge J, Cully M. Screen for Child Anxiety-Related Emotional Disorders (SCARED): convergent and divergent validity. Depress Anxiety. 2000;12(2):85-91. doi: 10.1002/1520-6394(2000)12:2<85::AID-DA4>3.0.CO;2-2.

31. Hale WW 3rd, Raaijmakers Q, Muris P, Meeus W. Psychometric properties of the Screen for Child Anxiety Related Emotional Disorders (SCARED) in the general adolescent population. J Am Acad Child Adolesc Psychiatry. 2005 Mar;44(3):283-90. doi: 10.1097/00004583-200503000-00013.

32. Weitkamp K, Romer G, Rosenthal S, Wiegand-Grefe S, Daniels J. German Screen for Child Anxiety Related Emotional Disorders (SCARED): Reliability, Validity, and Cross-Informant Agreement in a Clinical Sample. Child Adolesc Psychiatry Ment Health. 2010 Jun 30;4:19. doi: 10.1186/1753-2000-4-19.

33. Crocetti E, Hale WW 3rd, Fermani A, Raaijmakers Q, Meeus W. Psychometric properties of the Screen for Child Anxiety Related Emotional Disorders (SCARED) in the general Italian adolescent population: a validation and a comparison between Italy and The Netherlands. J Anxiety Disord. 2009 Aug;23(6):824-9. doi: 10.1016/j.janxdis.2009.04.003. Epub 2009 Apr 23.

34. Ogliari A, Citterio A, Zanoni A, Fagnani C, Patriarca V, Cirrincione R, Stazi MA, Battaglia M. Genetic and environmental influences on anxiety dimensions in Italian twins evaluated with the SCARED questionnaire. J Anxiety Disord. 2006;20(6):760-77. doi: 10.1016/j.janxdis.2005.11.004. Epub 2005 Dec 1.

35. Muris $\mathrm{P}$, Merckelbach $\mathrm{H}$, Ollendick $\mathrm{T}$, King N, Bogie N. Three traditional and three new childhood anxiety questionnaires: their reliability and validity in a normal adolescent sample. Behav Res Ther. 2002 Jul;40(7):753-72. doi: 10.1016/s0005-7967(01)00056-0.

36. Vigil-Colet A, Lorenzo-Seva U, Condon L. Development and validation of the statistical anxiety scale. Psicothema. 2008 Feb;20(1):174-80.

37. L. Su, K. Wang, F. Fan, et al. Reliability and validity of the screen for child anxiety related emotional disorders (SCARED) in Chinese children. J Anxiety Disord. 2008;22:612-21. doi: 10.1016/j.janxdis.2007.05.011.

38. Muris P, Loxton H, Neumann A, du Plessis M, King N, Ollendick T. DSM-defined anxiety disorders symptoms in South African youths: Their assessment and relationship with perceived parental rearing behaviors. Behav Res Ther. 2006 Jun;44(6):883-96. doi: 10.1016/j.brat.2005.06.002. Epub 2005 Aug 30. 
39. Hale WW 3rd, Crocetti E, Raaijmakers QA, Meeus WH. A meta-analysis of the cross-cultural psychometric properties of the Screen for Child Anxiety Related Emotional Disorders (SCARED). J Child Psychol Psychiatry. 2011 Jan;52(1):80-90. doi: 10.1111/j.1469-7610.2010.02285.x.

40. Karanevich,A., Garrard, L., Bott, M., Price, L., Gajewski, B. (2015) . Classical \& Bayesian Instrument Development, University of Kansas Department of Biostatistics , A web application for psychometric analyses, Reliability estimation using a web application , Sponsored by R03NR013236, web: http://biostatsshinyr.kumc.edu/CBID/.

41. Aminabadi NA, Pourkazemi M, Babapour J, Oskouei SG. The impact of maternal emotional intelligence and parenting style on child anxiety and behavior in the dental setting. Med Oral Patol Oral Cir Bucal. 2012 Nov 1;17(6):e1089-95. doi: 10.4317/medoral.17839.

42. Shaw WC. The influence of children's dentofacial appearance on their social attractiveness as judged by peers and lay adults. Am J Orthod. 1981 Apr;79(4):399-415. doi: 10.1016/0002-9416(81)90382-1.

43. de Jong PJ. Implicit self-esteem and social anxiety: differential self-favouring effects in high and low anxious individuals. Behav Res Ther. 2002 May;40(5):501-8. doi: 10.1016/s0005-7967(01)00022-5.

44. Young BJ, Bunnell BE, Beidel DC. Evaluation of children with selective mutism and social phobia: a comparison of psychological and psychophysiological arousal. Behav Modif. 2012 Jul;36(4):525-44. doi: 10.1177/0145445512443980. Epub 2012 May 7.

45. Agel M, Hipolito G. Dental care for children with selective mutism: How do we communicate effectively?. Faculty Dental Journal. 2021;12:72-77. 10.1308/rcsfdj.2021.18.

46. Fredrikson M, Annas P, Fischer H, Wik G. Gender and age differences in the prevalence of specific fears and phobias. Behav Res Ther. 1996 Jan;34(1):33-9. doi: 10.1016/0005-7967(95)00048-3.

47. McLean CP, Asnaani A, Litz BT, Hofmann SG. Gender differences in anxiety disorders: prevalence, course of illness, comorbidity and burden of illness. J Psychiatr Res. 2011 Aug;45(8):1027-35. doi: 10.1016/j.jpsychires.2011.03.006. Epub 2011 Mar 25.

48. Halasa S, Hamdan-Mansour AM, Salami I., Alenezi A. (2020). Post-traumatic stress and social anxiety among children of Syrian refugees in Jordan. International Journal of Mental Health and Addiction. First online., 18, 1611-1619. https://doi.org/10.1007/s11469-020-00250-y.

49. Arab A, El Keshky M, Hadwin JA. Psychometric Properties of the Screen for Child Anxiety Related Emotional Disorders (SCARED) in a Non-Clinical Sample of Children and Adolescents in Saudi Arabia. 47 Child Psychiatry Hum Dev, 554-562 (2016). https://doi.org/10.1007/s10578-015-0589-0.

50. Bucur SM, Păcurar M. Methods to reduce anxiety applied in the pedodontic practice. Romanian J Oral Rehabil. 2014; 6(2):70-5.

51. Ahuja V, Ranjan V, Passi D, Jaiswal R. Study of stress-induced temporomandibular disorders among dental students: An institutional study. Natl J Maxillofac Surg. 2018 Jul-Dec;9(2):147-154. doi: 10.4103/njms.NJMS_20_18.

52. de Paiva Bertoli FM, Bruzamolin CD, de Almeida Kranz GO, Losso EM, Brancher JA, de Souza JF. Anxiety and malocclusion are associated with temporomandibular disorders in adolescents diagnosed by RDC/TMD. A crosssectional study. J Oral Rehabil. 2018 Oct;45(10):747-755. doi: 10.1111/joor.12684.

53. Karibe H, Shimazu K, Okamoto A, Kawakami T, Kato Y, Warita-Naoi S. Prevalence and association of selfreported anxiety, pain, and oral parafunctional habits with temporomandibular disorders in Japanese children and adolescents: a cross-sectional survey. BMC Oral Health. 2015 Jan 21;15:8. doi: 10.1186/1472-6831-15-8.

54. Minervini G, Nucci L, Lanza A, Femiano F, Contaldo M, Grassia V. Temporomandibular disc displacement with reduction treated with anterior repositioning splint: a 2-year clinical and magnetic resonance imaging (MRI) follow-up. J Biol Regul Homeost Agents. 2020 Jan-Feb;34(1 Suppl. 1):151-160. DENTAL SUPPLEMENT.

55. Moccia S, Nucci L, Spagnuolo C, d'Apuzzo F, Piancino MG, Minervini G. Polyphenols as Potential Agents in the Management of Temporomandibular Disorders. Applied Sciences. 2020; 10(15):5305. https://doi.org/10.3390/app10155305.

56. Ajmal M, Ibrahim L, Mohammed N, Al-Qarni H. Prevalence and psychological stress in recurrent aphthous stomatitis among female dental students in Saudi Arabia. Clujul Med. 2018;91(2):216-221. doi: 10.15386/cjmed840. Epub 2018 Apr 25. PMID: 29785161; PMCID: PMC5958988.

57. Soto Araya M, Rojas Alcayaga G, Esguep A. Association between psychological disorders and the presence of Oral lichen planus, Burning mouth syndrome and Recurrent aphthous stomatitis. Med Oral. 2004 Jan-Feb;9(1):17. English, Spanish. 
58. Suresh KV, Shenai P, Chatra L, Ronad YA, Bilahari N, Pramod RC, Kumar SP. Oral mucosal diseases in anxiety and depression patients: Hospital based observational study from south India. J Clin Exp Dent. 2015 Feb 1;7(1):e95-9. doi: 10.4317/jced.51764. PMID: 25810851; PMCID: PMC4368027.

59. Chang B, Zhu W, Li S. Effects of Depression and Anxiety on Microvascular Decompression Outcome for Trigeminal Neuralgia Patients. World Neurosurg. 2019 Aug;128:e556-e561. doi: 10.1016/j.wneu.2019.04.194.

60. Mousavi SH, Sekula RF, Gildengers A, Gardner P, Lunsford LD. Concomitant depression and anxiety negatively affect pain outcomes in surgically managed young patients with trigeminal neuralgia: Long-term clinical outcome. Surg Neurol Int. 2016 Nov 15;7:98. doi: 10.4103/2152-7806.194145.

61. Shim YS, Kim AH, Jeon EY, An SY. Dental fear \& anxiety and dental pain in children and adolescents; a systemic review. J Dent Anesth Pain Med. 2015 Jun;15(2):53-61. doi: 10.17245/jdapm.2015.15.2.53. Epub 2015 Jun 30.

62. Roy J, Dempster LJ. Dental anxiety associated with orthodontic care: prevalence and contributing factors. Seminars in Orthodontics 2018;24:233-41.

63. B12Silva LCD, Vedovello SAS, Vedovello Filho M, Meneghin MC, Ambrosano Bovi GM, Degan VV. Anxiety and oral habits as factors associated with malocclusion. Cranio. 2021 May;39(3):249-253. doi: 10.1080/08869634.2019.1633492. Epub 2019 Jun 23.

64. Minervini G, Lucchese A, Perillo L, Serpico R, Minervini G. Unilateral superior condylar neck fracture with dislocation in a child treated with an acrylic splint in the upper arch for functional repositioning of the mandible. Cranio. 2017 Sep;35(5):337-341. doi: 10.1080/08869634.2016.1203560. Epub 2016 Jul 11. PMID: 27398739.

65. La Paglia F, Daino M, Guarino D, La Barbera D, Zichichi S, Riva G, Wiederhold Brenda. Virtual Reality Environments to Reduce Dental Anxiety in Annual Review of Cybertherapy and Telemedicine 2018. Annual Review of CyberTherapy and Telemedicine. 2019;16:167-170.

66. Raghav K, Van Wijk A, Abdullah F. et al. Efficacy of virtual reality exposure therapy for treatment of dental phobia: a randomized control trial. BMC Oral Health 16, 25 (2016). https://doi.org/10.1186/s12903-016-0186-z.

67. Bucur SM, Cires M, Gligor A, Pacurar M. Expert System for Determining the Level of Stress before Pediatric Dental Treatment. Procedia Technology. 2014;12:548-57. 10.1016/j.protcy.2013.12.528. 